\title{
In-silico approach: docking study of novel Schiff base congeners of pyrimidine nucleus
}

\begin{abstract}
Pyrimidine nucleus has a wide spectrum use in medicinal chemistry. Based on structure activity relationship of pyrimidine nucleus we are going to synthesize 4-amino-2-methyl6-phenylpyrimidine-5-carbonitrile derivatives. In this structure one primary amine group is free at $4^{\text {th }}$ position. Schiff base has excellent antibacterial, antifungal, antiviral activities due to presence of azomethine $(\mathrm{CH}=\mathrm{N})$ group. Schiff base compounds have extensive applications in various fields such as analytical, inorganic, organic, and biological fields. They have excellent pharmacology application prospects in the modern era and are widely used in the pharmaceutical industry. In the present work in silico docking studies of five Schiff base compounds were carried out against Staphylococcus aureus.
\end{abstract}

Keywords: schiff base, antimicrobial activity, In-silico study
Volume II Issue I - 2022

\author{
Dipanjan Karati, KR Mahadik, Dileep Kumar \\ Poona College of Pharmacy, Department of Pharmaceutical \\ Chemistry, Bharati Vidyapeeth, India
}

\begin{abstract}
Correspondence: Dileep Kumar, Assistant professor, Department of Pharmaceutical Chemistry, Poona College of Pharmacy, Bharati Vidyapeeth (Deemed to be University), Erandwane, Pune- 4/ 1038, Maharashtra, India, Email karatidipanjan@gmail.com
\end{abstract}

Received: October 21, 2021 | Published: February 21, 2022

\section{Introduction}

The research in the field of therapeutics is of great importance for the improvement of the quality of human life and for reducing human diseases. A vast number of diseases is due to pathogenic organisms. Pathogens are microorganisms that are harmful to the human body. Bacteria, viruses, fungus, prion, protozoan, viroid, etc. are the different types of pathogens. Microbial infections are drastically increased in living beings due to multidrug-resistant microorganisms even though the human body can defend against potential pathogens. ${ }^{1-3}$ S. aureus is one of such multi-drug-resistant microorganisms.

Because of their biological functions, pyrimidines and their oxo byproducts are six-membered heterocyclic compounds of significance for medicinal chemistry. These are similar to nucleic acids, as they are pretty much alike in structure to the pyrimidine bases. Maybe as an antitumor, antiviral, hypotensive, hypoglycemic, and antiinflammatory agents, substances with such heterocycles in their structure have been documented because of this structural similarity. ${ }^{4-8}$

Multicomponent reactions (MCRs) are one-pot synthetic processes that originate with the mixing of three or more reagents, but react in series. In general, these reactions are driven by an irreversible phase which, in favour of the final product, precedes balance. Here the proposed molecules can be synthesized by microwave (green approach of synthesis) assisted method with good yield.

\section{Brief attention on pyrimidine nucleus}

Pyrimidines are one of the fascinating heterocyclic compounds due to their vast range of biological activities in recent years. These compounds are of considerable importance because they represent an important class of natural and non-natural materials, many of which exhibit biological activities and therapeutic applications that are useful. ${ }^{9,10}$

SAR studies (Figure 1) offer insights into the molecular properties that induce affinity and selectivity of the receptor. Replacements in the hydrophobic domain can be due to the promising existence of the compounds. Structure Activity Relationship of Pyrimidine is as following

I. The insertion of five saturated heterocycle rings at the 1st position leads to anti-cancer and anti-viral operations.
II. If Keto group replacement or Amino substitution or combined substitution will be occurred at the $2^{\text {nd }}$ and $4^{\text {th }}$ positions of pyrimidine nucleus, then it leads to anti-cancer, anti-viral, antifungal activities.

III. Halogen groups, substituted amine group or heterocycles ring if will be placed at $5^{\text {th }}$ position of pyrimidine ring it will give anticancer, anti-bacterial activity.

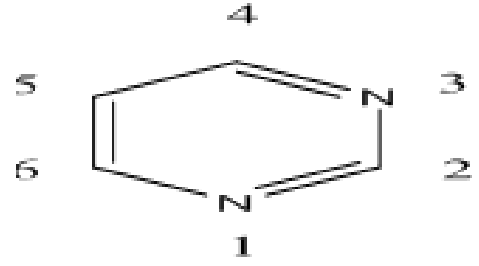

Figure I Pyrimidine nucleus.

\section{Schiff base scaffolds}

Double bond between Carbon-nitrogen plays a crucial role in the advancement of chemical science. Schiff bases are prepared by condensation of an amine and carbonyl compounds and these are significant types of ligands that coordinate to metal ions through azomethine nitrogen. ${ }^{9}$ It is regarded as a nitrogen analogue of an aldehyde or ketone where the imine group substitutes the $\mathrm{C}=\mathrm{O}$ group. Therefore, it is also known as imine or azomethine. The lone pair of electrons in the sp2 hybrid orbital of $\mathrm{N}$ atom in $-\mathrm{C}=\mathrm{NH}$ - linkage present in Schiff bases enhances their biological and chemical importance. ${ }^{10,11}$ Microwave assisted synthetic process of Schiff base is speedy and effectual with no use of solvent. The yield of products is also more and decontamination is done by modest recrystallization system. ${ }^{12}$ Azomethine nitrogen not only affords a binding site for metallic ions, but also binds to bio-molecules such as proteins and amino acids in biological systems and to germ-causing diseases with different substrates. Azomethine group helps to prevent the synthesis of histamine, prostaglandin, 5 hydroxy tryptamines in body which leads to provide several antimicrobial activities.

\section{Materials and methods}

The process of docking, interaction, and binding the structure of ligand with protein has executed using Auto dock Vina software. 
Preparation of ligands and proteins- Chem-draw software was used to determine the structure of the Schiff bases in MOL format. The protein structure was downloaded in PDB format using RCSB PDB. Using Auto dock Vina, water molecules and ligands already present in the proteins were removed, and hydrogen atoms were added and saved in PDB format. 2D and 3D representation of the compounds have represented by Figure 3-5. Prediction of active site- In structurebased drug design, the active site prophecy is critical. The program BIOVIA Discovery Studio was used to calculate the coordinates of the proteins' binding locations.

\section{Results and discussion}

Schiff bases (Figure 2) are generally prepared by the condensation of carbonyl compounds (aldehyde/ketones) with aromatic or aliphatic primary amines. ${ }^{13}$ To identify the mechanism by which the chemicals restrict S. aureus development, a molecular docking research (insilico study) was undertaken. The Schiff bases have a high affinity for the dihydrofolate reductase enzyme, which was the target protein (PDB ID: 2W9S) Table 1. ${ }^{14-19}$

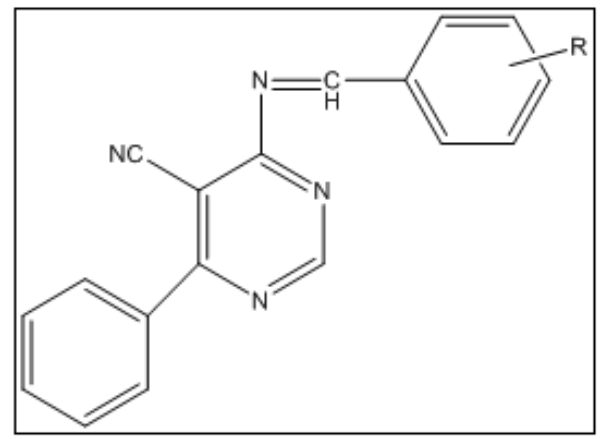

Figure 2 Schiff base scaffolds.
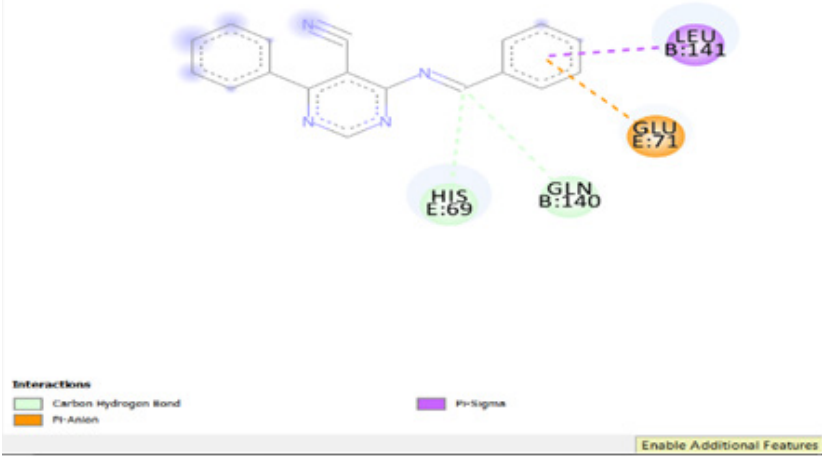

Figure $32 \mathrm{D}$ interaction.

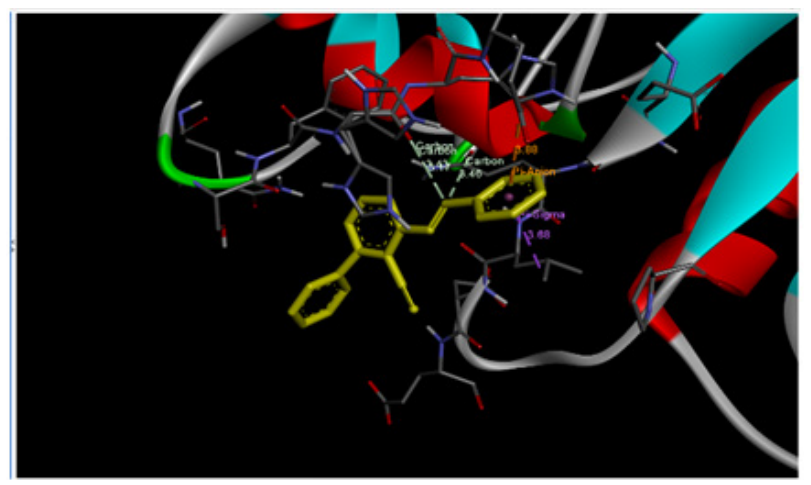

Figure 4 3D interaction.

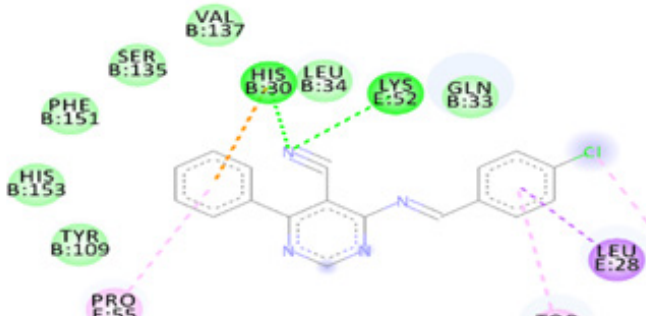

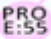
Trop
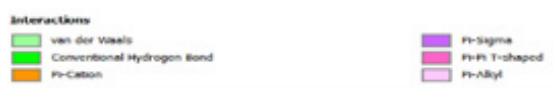

Figure $52 \mathrm{D}$ interaction.

Table I Binding energy

\begin{tabular}{llll}
\hline SL. N. & Drug molecule & R & $\begin{array}{l}\text { Binding energy } \\
(\mathbf{k c a l} / \mathbf{m o l})\end{array}$ \\
\hline $\mathrm{I}$ & Benzene derivative & $\mathrm{H}$ & -6.7 \\
2 & Chloro benzene & $\mathrm{p}-\mathrm{Cl}$ & -8.1 \\
3 & Dinitrobenzene & $\mathrm{m}, \mathrm{p}-\mathrm{NO} 2$ & -7 \\
4 & Methoxybenzene & $\mathrm{p}-\mathrm{OCH} 3$ & -6.4 \\
5 & Nitrobenzene & $\mathrm{p}-\mathrm{NO} 2$ & -8.5 \\
\hline
\end{tabular}

\section{Docking figure for compound I-}

\section{Docking figure for compound 2-}

Hydrogen bond interactions such as conventional and nonconventional $\mathrm{H}$ bonds, hydrophobic interactions such as amide-pi stacked, pi-pi stacked, pi-sigma, pi-pi T-shaped, alkyl and pi-alkyl interactions, electrostatic interactions such as pi-anion and pi-cation interactions, van der Waals interaction, and unfavourable donordonor and acceptor-acceptor interactions are commonly seen between protein and ligand. The sum of all interactions and binding energy between the chemical and the target protein determines its binding affinity. Binding energies of the compounds have been noted in Table 1.

\section{Conclusion}

For chloro and nitro scaffolds docked with $2 \mathrm{~W} 9 \mathrm{~S}$, maximum binding energies of -8.1 and $-8.5 \mathrm{kcal} / \mathrm{mol}$ were observed, indicating that the significant growth-inhibitory power of these Schiff bases against the pathogenic bacteria $\mathrm{S}$. aureus is primarily due to deactivation of the enzyme dihydrofolate reductase.

Interactions with amino acid residues-

Vander Waals bond- VAL137, SER135, PHE151, TYR109.

Hydrogen bond- HIS30, LYS52, HIS23.

\section{Pi-Sigma- LEU141, PRO55.}

We can conclude from the result of docking study of these novel compounds that the scaffolds having $\mathrm{Cl}$ and $\mathrm{NO}_{2}$ groups substitution (containing negative inductive effect) will be excellent drug congeners against DHFR enzyme for treatment of $S$ aureus bacterial infection. 


\section{Acknowledgments}

Dipanjan Karati is thankful to the All-India Council for Technical Education (AICTE), New Delhi, India for awarding a fellowship.

\section{Conflicts of interest}

There is none among the others.

\section{Funding}

None.

\section{References}

1. Takeuchi A, Sprinz H, LaBrec EH, et al. Experimental bacillary dysentery. An electron microscopic study of the response of the intestinal mucosa to bacterial invasion. Am J Pathol. 1965;47(6):1011-1044.

2. Mel D, Gangarosa EJ, Radovanović ML, et al. Studies on vaccination against bacillary dysentery. 6 . Protection of children by oral immunization with streptomycin-dependent Shigella strains. Bull World Health Organ. 1971;45(4):457-464.

3. Kaur S, Modi NH, Panda D, et al. Probing the binding site of curcumin in Escherichia coli and Bacillus subtilis FtsZ-a structural insight to unveil antibacterial activity of curcumin. Eur J Med Chem. 2010;45(9):42094214.

4. Stringfellow DA. Antinociceptive pyrimidine derivatives: aqueous multicomponent microwave assisted synthesis. Adv Enzyme Regul. 1981;19:335-348.

5. Scheringa M, Ijzermans JN, Jeekel J. The antitumour activity of the interferon inducer bropirimine is partially mediated by endogenous tumour necrosis factor. Cancer Immunol Immunother. 1990;32:251-255.

6. Saladino R, Ciambecchini U, Maga G, et al. Comparative Computational Studies of 3,4-Dihydro-2,6-diaryl-4-oxo-pyrimidine-5-carbonitrile Derivatives as Potential Antinociceptive Agents. Med Chem. 1995;38:4806-4820.
7. dos Anjos JV, Mendonça FJB, Jr Costa-Silva, Comparative Computational Studies of 3,4-Dihydro-2,6-diaryl-4-oxo-pyrimidine-5-carbonitrile Derivatives as Potential Antinociceptive Agents. Lat Am J Pharm. 2008;27:809-819.

8. Kumar S, Narasimhan B. Therapeutic potential of heterocyclic pyrimidine scaffolds. Chem Cent J. 2018;12:38.

9. Mahapatra A, Prasad T, Sharma T. Pyrimidine: a review on anticancer activity with key emphasis on SAR. Future Journal of Pharmaceutical Sciences. 2021;7:123.

10. Patai S. The chemistry of Carbon-Nitrogrn double bonds. John Willey and Sons Ltd. 1970.

11. Singh P, Goel RL, Singh BP. 8-acetyl-7-hydroxy-4- methyl coumarin as a gravimetric reagent for $\mathrm{Cu} 2+$ and Fe3+. J Indian Chem Soc. 1975;52:958959.

12. ElmaliKM,Elerman Y. Keto-enol tautomerism, conformations and structure of N-(2-hydroxy-5- methylphenyl), 2-hydroxybenzaldehydeimine. J Mol Struct. 2000;477:151-158

13. Yang HJ, Sun WH, Li ZL, et al. The rapid synthesis of Schiff base without solvent under microwave irradiation. Chinese chemical Letters. 2002;13(2002):3-6.

14. Schiff H. Mittheilungen aus dem Universitätslaboratorium in Pisa: Eine neue Reihe organischer Basen. Justus Liebigs Ann Chem. 1864;131(1):118-119.

15. Ragi K, Kakkassery JT, Raphael VP, et al. In vitro antibacterial and in silico docking studies of two Schiff bases on Staphylococcus aureus and its target proteins. Future Journal of Pharmaceutical Sciences. 2021;7:78

16. Ogston A. Classics in infectious diseases. Rev Infect Dis. 1984;6(1):122128.

17. Kluytmans J, Belkum AV, Herbrugh V. Nasal carriage of Staphylococcus aureus: epidemiology, underlying mechanisms, and associated risks. Clin Microbiol Rev. 1997;10(3):505-520.

18. Cole AM, Tahk S, Oren A, et al. Determinants of Staphylococcus aureus nasal carriage. Clin Diagn Lab Immunol. 2001;8(6):1064-1069. 